\title{
Psychological Well-being of Police Officers and Its Impact on the Level of Job Commitment and Quality of Social Relationships
}

\author{
Areen Mohammed Alghzewat Alkhawaldeh ${ }^{1} \&$ Ayman Ahmad Alkrimeen ${ }^{2}$ \\ ${ }^{1}$ Department of Counseling and Mental Health, The World Islamic Sciences and Education University, Jordan \\ ${ }^{2}$ Criminology, Department of Police Sciences, Police College (Qatar), Qatar \\ Correspondence: Areen Mohammed Alghzewat Alkhawaldeh. E-mail: areen3010@ hotmail.com
}

Received: April 27, 2020

doi:10.5539/ass.v17n1p91
Accepted: May 16, $2020 \quad$ Online Published: December 30, 2020

URL: https://doi.org/10.5539/ass.v17n1p91

\begin{abstract}
This study aimed at examining the effect of an employee's sense of psychological well-being at work and the quality of social work relationships (the relationship between colleagues and the relationship with superiors) on the level of job commitment; the study was conducted on 80 police officers working in the Police College (Qatar), four measures were used to measure study variables. The regression analysis results indicated a positive correlation between the sense of psychological well-being at work and career commitment to the high level of social relations at work. Note that this study makes a set of significant contributions to the Arab work environment, whether at the theory or practice level. The study's most important results indicate the necessity of giving social work relations the appropriate attention, given its significant role in several organizational and individual outputs, which departments are rarely interested in.
\end{abstract}

Keywords: psychological well-being at work, work relationships, job commitment, work design

\section{Introduction}

The concept of Psychological Well- being- is the central concept in positive psychology because of its prominent position in human thought history. Everyone in different cultures has sought happiness as a higher goal of life as it is linked to the state, the positive mood, the positive attitude, satisfaction with life, quality, self-realization, and optimism (Assaied, 2010). This meaning is considered to be somewhat close to the concept of quality of life, which means the individual's happiness, and satisfaction to achieve meaning in life and to achieve its goals and unique values, which is the product of his ability to develop and grow in a manner that makes him able to achieve his goals to live and act freely, happily, and become a clear and consistent good. This concept of psychological happiness interferes with some other concepts, which are (feeling comfortable - satisfaction with life - enjoyment in life - psychological compatibility - achievement - psychological security - contentment) (Hasan, 2010). Although the primary goal of psychology is to help the individual to lead a long life in which he feels happy, psychologists have for many years ignored the positive personal feelings and negative emotions such as anxiety, depression, psychological pressure, and pessimism are the most frequently discussed and interested in their research and studies.

Psychological happiness is a key concept in positive psychology because of its prominent position in human thought history. Different cultures have sought to reach happiness as a higher goal of life because of its connection with positive moods, satisfaction with life and quality, self-realization, and optimism; this concept interferes with some other positive concepts such as feeling comfortable, psychological well-being, and psychological well-being (psychological well-being), satisfaction with life, enjoyment in life, psychological compatibility, achievement, and psychological security, contentment and tranquility, and good-living (El-Gundy, Abdel-Talahmeh, 2017).

Happiness is a relative matter that differs from one person to another. The patient sees that happiness in health, and the poor see that happiness in wealth, and the older adult may know that happiness in the days of young people that are gone, while the prisoner sees happiness in freedom. There are many types of happiness and patterns; it is formed according to the individual's vision of it or the missing part. The feeling of psychological happiness (Psychological well-being) is one of the psychological concepts that has received significant attention from researchers in psychology and mental health; this is because they consider this concept an essential indicator for necessary adaptation and good mental health. As for feeling unhappy, it is one of the crucial 
problems in the life of today's human being, as this problem is considered as a starting point for many of the problems that a person suffers from and complains about; this feeling is often supported by other problems that existed in the individual's life before he felt unhappy (Abdel Wahab, 2006).

\subsection{The Importance of the Study}

The traditional role of psychology has been confined for many decades to focusing on studying the negative aspects of the human personality and neglecting its positive qualities, where psychology has been concerned with repairing damages and treating mental disorders more than its interest in helping individuals in a productive and satisfactory life and developing their capabilities and capabilities necessary for growth. However, there is a new trend that is gaining more supporters, and that is positive psychology, thanks to its founding in the world Martin Seligman in the eighties of the last century. This approach focuses on understanding these individuals who live in overwhelming happiness, wisdom, psychological fitness, and kindness on the physical and psychological levels and help others gain and develop their strengths. These capabilities allow individuals to grow and thrive, mitigating the effects of hardship, and preventing mental and physical illness (Khalifa, 2009).

In light of this trend and its supporters, the person who enjoys mental health is not the person who is free of illness; the origin is health, not a disease. A person can adapt and conform to his society if he focuses on the positive aspects of his life and transmits hope, optimism, happiness, contentment and enjoyment of relationships with himself and others, Psychological resilience, etc. (Selim, 2010). This broad interest in the positive aspects of mental health has led to the development of numerous models to define the basic features and indicators of well-being, as many models have emerged that differ in their interpretation and vision of this concept (Ryan \& Deci, 2001)

\subsection{The Problem of the Study and Its Importance}

This study's importance comes in trying to shed light on the psychological aspect of work-life; it is the psychological well-being, job commitment, and its impact on the quality of social relationships between colleagues and the quality of the relationship between managers and employees. The modern orientation of the International Labor Organization indicated that any practice of human resources departments should be directed towards two parallel goals: increasing productivity and achieving happiness for workers. This study is consistent with this approach, as psychological well-being is closely related to the concept of happiness at work, while job commitment is closely related to productivity. Few studies have examined the topic of psychological well-being and its relationship to job commitment among police officers. Therefore, this study comes to try to bridge the shortage in this field, and it provides a field study on the category of police officers at the Police College in Qatar.

\subsection{Study Hypotheses}

This study seeks to verify the following hypotheses:

The first hypothesis: The quality of relationships between co-workers is positively related to the level of job commitment employees show towards their work.

The second hypothesis: The quality of the relationship between co-workers is positively related to employees' feeling of psychological well-being at work.

The third hypothesis: The quality of the relationship between managers and police officers positively correlates with police officers' level of career commitment.

The fourth hypothesis: The quality of the relationship between managers and police officers positively correlates with the level of police officers' sense of psychological well-being at work.

\subsection{Previous Studies}

Mohanty\& Sahoo (2015) conducted a study aimed to study the role of personality type and gender on the concept of self and psychological happiness (psychological well-being (among a sample of university students totaling 200) male and female students. The study revealed that female students enjoy a higher-level concept of psychological happiness than their male counterparts, as the survey revealed a tremendously positive relationship between the concept of self and psychological pleasure.

Chui \& Wong (2015) study tackled the gender difference between adolescents in happiness and satisfaction with life and its relationship to the concept of self. The study sample consisted of (142) adolescents, the results indicated that self-esteem and the existence of a goal for life lead to increased happiness and satisfaction with life, and the presence of more close friends leads to a higher level of feeling of psychological happiness, but not higher satisfaction with life. On the other hand, the study revealed that males with academic achievements are 
necessarily the highest (Academic achievement is a component of self-concept) they are happier, and vice versa applies to females.

Al-Mutairi (2017) conducted a study to build a negative, structured model of the relationship between psychological happiness, self-esteem, and aggressive behavior among drug addicts. As the study revealed, psychological happiness can be predicted from the self-esteem of drug addicts.

Mahmoud's study (2018) sought to know the relationship between psychological flow and the level of ambition among a sample of fourth-year students at the Faculty of Education from Ain Shams University and also aimed to identify the impact of variables gender (male-female), academic specialization (scientific-literary), the results resulted in a positive correlation between psychological flow, all dimensions, and the overall degree of the ambitious scale, except the "desire to change for the better" dimension. The study also revealed no statistically significant differences between the mean of the individuals of the sample according to gender (male-female) in the psychological flow scale.

The study of Al-Masa et al. (2019) aimed to reveal the relationship between motivation towards academic achievement and psychological flow, and about the possibility of predicting the motivation of academic achievement in the psychological flow of high school students in the State of Kuwait, as the number of participants reached (178) students. The study leads to the following results: There is a relationship between the motivation of academic achievement and psychological flow except for the sense of time, and the presence of statistically significant differences between high and low psychological flow, as educational attainment can be predicted through the psychological flow.

Khatatba (2019) study aimed to reveal the relationship between self-management skills and psychological well-being among students of Imam Muhammad bin Saud Islamic University. The sample of the study consisted of (588) male and female students. The study respondents responded to the self-management skills scale prepared by Mansour, Abdel-Moneim, and Rayyan (2015), and the psychological well-being scale designed by Shand, Wahiba, and Salouma Abdel-Hamid (2013). The study results indicated a statistically significant relationship between the overall degree of the self-management scale and the psychological well-being scale. A statistically significant relationship was found at the level of significance (0.05) and less between some dimensions of the scale of self-management skills (self-organization, time management, optimism, managing social relationships, managing stress, self-confidence, self-motivation, making decisions, self-control) and some dimensions of the measure of psychological well-being (goal in life, self-acceptance, independence, positive relationships with others, personal maturity, and mastery From the environment, the total score Scale of psychological well-being). The results also showed that the arithmetic averages and the standard deviations for the scale of self-management skills came at a high level, where optimism dimension came the highest of these skills, while it came after self-control in the lowest self-management skills, and the arithmetic mean for psychological well-being came at a high level where the self-acceptance dimension ranked first with the highest average, followed by the fifth dimension: personal maturity in second place, in the last place, while the goal in life came in the lowest average the results showed that there were no statistically significant differences in all self-management skills, and a measure of psychological well-being according to the gender variable, especially some dimensions of the psychological well-being scale that showed that the differences were in favor of males compared to females, and that there were no statistically significant differences attributable to the impact of the educational level and economic level The majority of dimensions of the scale of self-management skills (the second dimension of time management, the fourth dimension of social relations management, the fifth dimension after stress management, and the ninth dimension of self-control, and the total degree of the tool). There were also statistically significant differences on all dimensions of the psychological well-being scale according to the educational level and the economic level on some dimensions and to varying degrees in terms of the academic level and the study personnel's economic level. Finally, the study results showed the possibility of predicting psychological well-being through the dimensions of self-management skills among students of Imam Muhammad bin Saud Islamic University.

\section{Study Methodology and Procedures}

\subsection{Study Methodology}

Based on the study hypotheses, a relational descriptive approach was used to reveal the relationship between the study variables.

\subsection{Study Procedures}

\subsubsection{Sample of the Study}


Data were collected by (80) directors and police officers at the Police College in Qatar in 2019.

\subsubsection{Tools of the Study}

The study tools included four global scales that were widely used in psychological well-being research at work. A preliminary study was conducted on the scales so that it was applied to ten police officers in an interview manner to ensure that the items are easy to understand and do not contain ambiguous words or need to be understood at a high educational level; none of the participants mentioned any vague items or vague terms.

The study tools included the following scales:

a. The relationships between colleagues: This dimension was measured through three items derived from a scale developed by the researchers Koys and Decotis, 1991. The items measure friendliness and mutual respect between colleagues. In addition to the extent of support that individuals receive from their colleagues, "Example: I can count on my colleagues when I ask for their support."

b. The relationship between supervisors and workers: The scale measures dimensions, such as: forming positive relationships with employees (example: my direct manager treats me respectfully), helping workers to develop their work skills, encouraging workers, and providing support to them (example: direct managers treat everyone fairly), and demonstrate competency in managing people.

c. Job commitment: The scale has been widely used in job research and worker questionnaires, an example of items (I used to feel proud when I tell people where I work, and sometimes I feel like I want to leave this work forever).

d. Job-related well-being: The scale consists of six items that measure depression-enthusiasm during the past month. Example: Did your job make you feel excited last month)?

\subsection{Procedures of the Study}

The questionnaire was distributed to the directors and police officers directly by the researcher, through small groups, the method for answering the measures was clarified, and what the different degrees mean on the different scales, as all police officers were followed up, and their inquiries were answered directly.

\subsection{Statistical Analysis}

The data was analyzed using SPSS packages. Initially, the collected data was revised by deleting items that contain incomplete data, which resulted in the deletion of two items, and the final statistical sample included (80) cases only. Descriptive statistics were initially applied to the data, whereby mean, standard deviations, and Pearson correlation coefficients were extracted for all study variables. To verify the question and the hypotheses of the study, a series of analyzes of linear regression and gradient regression (Hierarchal Regression) were performed, where the independent variables (work relationships) were introduced as the main factors in predicting the dependent variables, which are job commitment and psychological well-being at work.

\section{Results of the Study}

This study aimed to investigate the degree of correlation of social work relationships with the level of job commitment and the level of workers' psychological well-being. Initially, descriptive statistics were conducted to know the nature of the sample distribution and the type of relationships between the study variables. Table 1 shows descriptive statistics of study variables in terms of means, standard deviations, and Pearson correlation coefficient between all study factors.

Table 1. The study variables' descriptive statistics and the Pearson correlation coefficient among all the study factors

\begin{tabular}{ccccccccccc}
\hline & $\mathrm{N}$ & $\begin{array}{c}\text { The highest value } \\
\text { for the scale }\end{array}$ & Mean & $\begin{array}{c}\text { Standard } \\
\text { deviation }\end{array}$ & 1 & 2 & 3 \\
\hline Relationships between colleagues & 80 & 12 & 10.27 & 1.96 & 1 & & \\
Relations with managers & 80 & 32 & 26.30 & 5.22 & $0.46^{*}$ & 1 & \\
Job commitment & 80 & 36 & 28.42 & 5.02 & $0.31^{*}$ & $0.39^{*}$ & 1 & \\
Depression - Enthusiasm & 80 & 28 & 15.17 & 2.29 & 0.12 & $0.37^{*}$ & 0.5 & 1 \\
\hline
\end{tabular}

${ }^{*}$ Correlation coefficient is statistically significant at the level $(\alpha=0.05)$

Looking at this table, we find that the level of relationships between colleagues was only correlated with the level of job commitment, \{correlation (80) $0.31=\alpha=0.05$, and was not correlated with the level of psychological well-being. The level of relationships with superiors correlates with feelings of depression enthusiasm $\{$ correlation $\{(80)=0.37, \alpha=0.05)\}$ and with the level of job commitment $\{$ correlation $\{(80)=0.39$, 
$\alpha=0.05)\}$.

Hypothesis No. 1 indicated a positive relationship between the quality of relationships between colleagues and the level of job commitment. Hypothesis No. (2) also indicated a positive relationship between the quality of relationships between colleagues and the level of feeling of psychological well-being at work. To confirm these hypotheses, a series of regression analyzes were performed. The level of relationships among colleagues was entered as an independent factor for predicting the level of both job commitment and psychological well-being (feeling of enthusiasm - depression). The regression analysis results indicated, as Table 2 indicates a positive relationship between the level of relationship between colleagues and the level of commitment the employee shows towards his job $\{t=2.72, \alpha=0.05\}$. "Relationships between Colleagues" and the level of feeling depressed - enthusiasm, noting that there is no statistically significant relationship. These are results that provide support for the first hypothesis and a rejection of the second hypothesis.

Hypothesis No. (3) indicated a positive relationship between the quality of the relationship with the managers and job commitment. Hypothesis No. (4) also indicated a positive relationship between the quality of the relationship with the managers and the level of feeling of psychological well-being in work, shown in Table No. (2). The results also indicated a positive relationship with a significant level between the relationship with managers and the level of feelings of enthusiasm - depression among employees $\{t=3.22, \alpha=0.05\}$. It also indicated a statistically significant relationship between the level of relationship with managers and the degree of employee commitment to the employee $\{t=2.55, \alpha=0.05\}$. These results indicate the fulfillment of the two hypotheses: the third and the fourth.

Table 2. Results of linear regression analysis between the quality of the relationship between colleagues and managers, and both job commitment and the level of psychological well-being

\begin{tabular}{|c|c|c|c|}
\hline Variables & $\beta$ & $\mathrm{t}$ & $\mathrm{R} 2 \Delta$ \\
\hline \multicolumn{4}{|l|}{ Dependent variable: job commitment } \\
\hline The quality of the relationship between colleagues & 0.31 & 2.73 & $* 0.09$ \\
\hline Quality of relationship with managers & 0.28 & 2.55 & $* 0.07$ \\
\hline \multicolumn{4}{|l|}{ Dependent variable: psychological well-being } \\
\hline The quality of the relationship between colleagues & 0.12 & 0.95 & 0.02 \\
\hline Quality of relationship with managers & 0.37 & 3.22 & $* 0.012$ \\
\hline
\end{tabular}

*The relationship is statistically significant at the level of $\alpha=0.05$

The last analysis aims to answer the study question, related to the size of the link between social work relationships and both commitment and psychological well-being at work, and their ability to explain the variance in the relationship. To answer this question, it included relationships between colleagues and relationships with managers as independent factors for predicting both job commitment and the level of psychological well-being of police officers. The results indicated, as indicated in Table 3 that social relations at work were able to explain the value (9\%) of the variance in the level of commitment and (12\%) of the level of disparity in the mental health of police officers. Overall, the size of the contrast Expositor relationships between colleagues higher when the worker is a career commitment. But when the worker is to be the psychological well-being, the size of the contrast Expositor relations between the Chairperson-be subordinate is the highest; this means that relationships between colleagues are more closely related to job commitment, while relationships with managers are more connected with the level of feelings of psychological well-being at work.

Table 3. Hierarchal regression between the quality of the relationship between colleagues and managers, and both job commitment and the level of feeling of psychological well-being

\begin{tabular}{|c|c|c|c|}
\hline Variables & $\beta$ & $\mathrm{t}$ & $\mathrm{R} 2 \Delta$ \\
\hline \multicolumn{4}{|l|}{ Job commitment } \\
\hline \multicolumn{4}{|l|}{ The first step } \\
\hline The quality of the relationship between colleagues & 0.27 & 2.15 & $* 0.09$ \\
\hline Quality of relationship with managers & 0.07 & 0.50 & - \\
\hline \multicolumn{4}{|l|}{ Psychological well-being } \\
\hline \multicolumn{4}{|l|}{ The first step } \\
\hline Quality of relationship with managers & 0.39 & 3.09 & 0.13 \\
\hline The quality of the relationship between colleagues & 0.08 & 0.53 & - \\
\hline
\end{tabular}




\section{Discussion of the Results}

This study aimed to determine the degree of correlation of the quality of social work relationships with the level of job commitment and psychological well-being of police officers. Four hypotheses were examined in this study, three of which were accepted. The study's general results indicated an association between social work relationships (the relationship between colleagues, the relationship with managers) to the level of job commitment and psychological well-being at work and, this indicates the importance of such factors in the work environment due to its predictive ability with a set of organizational and individual outputs alike. A discussion of the theoretical and practical applications of the results of this study follows.

\subsection{The Psychological Well-Being of Workers and the Quality of Social Work Relationships}

The regression analysis results indicated a positive relationship with statistical significance between the level of relationship with superiors and the level of feeling depressed-enthusiastic. In other words, the better the relationship with the managers, the more likely the police officer will get excited and the less depressed and lethargic he will feel. This result is an actual result of multiple theoretical and practical applications. This finding supports several studies, which indicate the influence of leadership style on motivation and mental health in general. Contrary to what was expected, there was no positive relationship between the quality of relationships between colleagues and the level of psychological well-being of police officers, although previous studies indicated a positive relationship. A possible explanation for the outcome is the way to measure social relationships between colleagues. The scale used in this study was a general measure that revolves around a positive, medium-quality fellowship relationship. It measures mutual respect and the degree of assistance, but it does not measure the degree of openness to intimacy or the degree of intimacy.

\subsection{Quality of Social Work Relationships and the Extent of Job Commitment}

Regression analysis results indicated that relationships between colleagues are associated with police officers' level of job commitment. This result indicates the importance of relationships with colleagues in the work environment. Note that this study's outputs are not surprising, as some studies indicated that the employee who has bad relations with his colleagues feels ostracized, alienated, and not merging with work or his tasks. In addition to the above, the regression analysis results indicated a positive correlation between the level of relationship with managers and the level of job commitment demonstrated by the police officer. This result is significant, as it indicates that the manager may be a driver expelling his hands' competencies. We all know that a manager can elevate his workers to the highest levels of productivity and loyalty, and he can be an alienating person who pushes police officers into indifference, indifference, and non-affiliation.

\section{References}

Abdel-Wahab, A. (2006). Psychological happiness and its relationship to some psychological variables among a sample of teenagers from both sexes. Journal of Psychological and Educational Research, 21(2), 254-308.

Al-Gundy, N., \& Abdel-Talahmeh, J. (2017). The degrees of the feeling of psychological well-being among Palestinian university students in the Hebron governorate. Journal of Educational and Psychological Studies, 11(2), 337-351. https://doi.org/10.24200/jeps.vol11iss2pp337-351

Al-Masa, M., Abd Allah, H., \& Ajajah, S. (2019). Predicting the motivation for academic achievement from the level of psychological flow among high school students in Kuwait's State. The Arab Journal of Educational and Psychological Sciences, (11), 233-268.

Al-Mutairi, K. (2017). Building a negative, structured model of the relationship between psychological happiness, self-esteem, and aggressive behavior among drug addicts (Unpublished Ph.D. thesis) Naif Arab University for Security Sciences, Saudi Arabia.

Assaied, M. (2010). The structural model of relationships between psychological happiness and the five major factors of personality, self-esteem and social support among university students. Journal of the College of Education. Benha University.

Chui, W. H., \& Wong, M. Y. (2016). Gender differences in happiness and life satisfaction among adolescents in Hong Kong: Relationships and self-concept. Social Indicators Research, 125(3), 1035-1051. https://doi.org/10.1007/s11205-015-0867-z

Hasan, N. (2010). The quality of life for university students. Civilized Dialogue Group.

Katatba, Y. (2019). Self-management skills and their relationship to psychological well-being for students of Imam Muhammad bin Saud Islamic University. The Journal of Humanities and Social Sciences, (54) 
Khalifa, A. (2009). Happy Activities and Events for University Students. Annals of the Center for Research and Psychological Studies, 5(5), 1-64.

Mahmoud, H. (2018). Psychological flow and its relationship to the level of ambition among a sample of a student of the Faculty of Education. Journal of the Faculty of Education in Psychological Sciences, 11(42), 104-277.

Mohanty, N., \& Sahoo, P. (2015). Self-concept and well-being of young adults: An empirical study. Indian Journal of Health and Wellbeing, 6(1), 8-12.

Okasha, M., \& Selim, I. (2010). The relationship between the quality of psychological life and language disability. A working paper, presented to the Faculty of Education's seventh scientific conference at Kafr El-Sheikh University entitled "Quality of Life as an Investment for Educational and Psychological Sciences."

Ryan, R., \& Deci, E. (2001). On Happiness and Human Potentials: A review of Research on Hedonic and Eudaemonic Well-Being. Annual Review of Psychology, 52, 141-166. https://doi.org/10.1146/annurev.psych.52.1.141

\section{Copyrights}

Copyright for this article is retained by the author(s), with first publication rights granted to the journal.

This is an open-access article distributed under the terms and conditions of the Creative Commons Attribution license (http://creativecommons.org/licenses/by/4.0/). 